\title{
Nitrogen-doped Porous Carbon Derived from Chitin with Enhanced Performances for Oxygen Reduction Reaction and Supercapacitor
}

\author{
Lei Yao ${ }^{1,2}$, Wenhua Zhong ${ }^{2}$, Lei Qiu ${ }^{2}$ and Libo Deng ${ }^{2, *}$ \\ ${ }^{1}$ College of Environmental Sciences and Engineering, Peking University, The Key Laboratory of \\ Water and Sediment Sciences, Ministry of Education, Beijing 100871, China \\ ${ }^{2}$ College of Chemistry and Environmental Engineering, Shenzhen University, Shenzhen 518060, \\ China \\ E-mail: Denglb@szu.edu.cn
}

doi: $10.20964 / 2018.06 .67$

Received: 17 February 2018 / Accepted: 10 April 2018 / Published: 10 May 2018

\begin{abstract}
Herein a porous carbon with a high content of nitrogen, high surface area and high degree of graphitization was prepared by pyrolysing a cheap and abundant biopolymer chitin in the presence of both $\mathrm{FeCl}_{3}$ and $\mathrm{ZnCl}_{2}$. It was found the electrochemical performance is significantly dependent on the carbonization temperature. The $1000{ }^{\circ} \mathrm{C}$-treated carbon exhibited high electrocatalytic activity as catalysts for oxygen reduction reaction (ORR), showing a four-electron oxygen reduction pathway with an onset potential of $0.978 \mathrm{~V}$ (against reversible hydrogen electrode, RHE). The porous carbon also exhibited a capacitance of $130 \mathrm{~F} / \mathrm{g}$ at $0.5 \mathrm{~A} / \mathrm{g}$ and excellent rate performance as electrode for supercapacitors. These results are attributed to the high surface area, as well as the high degree of graphitization which endows the as-prepared carbon with a high electrical conductivity.
\end{abstract}

Keywords: Biomass, porous carbon, chitin, oxygen reduction reaction, supercapacitor

\section{$\underline{\text { FULL TEXT }}$}

(C) 2018 The Authors. Published by ESG (www.electrochemsci.org). This article is an open access article distributed under the terms and conditions of the Creative Commons Attribution license (http://creativecommons.org/licenses/by/4.0/). 